\title{
Analisis Pengendalian Piutang Pada Koperasi Pegawai Republik Indonesia (KPRI) Karya Dharma Kabupaten Tolitoli
}

\author{
Analysis Of Accounts Receivable Control At The Indonesian Republic Employee Cooporative \\ (KPRI) ToliToli Regerency Dharma Works
}

\author{
Muhammad Sujai', Kiki Fatmala ${ }^{2}$ \\ Manajemen, Sekolah Tinggi Ilmu Ekonomi Mujahidin \\ 1(muhammadsujai200@gmail.com), ${ }^{2}$ (kikipatmala19980808@gmail.com)
}

\begin{abstract}
Abstrak
Analisis pengendalian piutang pada koperasi pegawai Republik Indonesia (KPRI) karya Dharma Kabuapaten Tolitoli. Adapun yang menjadi tujuan dalam penelitian ini adalah untuk mengetahui tingkat efektivitas pengendalian piutang ditinjau dari besarnya pinjaman bermasalah selama 3 tahun terakhir pada KPRI Karya Dharma Kabupaten Tolitoli yang beralamat di Jln RA. Kartini No 17. Metode penelitian yang digunakan dalam penelitian ini yakni deksriptif kuantitatif. Jumlah sampel dalam penelitian ini, menyangkut data yang digunakan selama periode (tiga) tahun yakni mulai tahun 2016 sampai dengan tahun 2018 dengan mengkhususkan data-data yang menyangkut data pinjaman. Alat analisis yang digunakan yaitu Rasio Pinjaman Bermasalah terhadap pinjaman yang diberikan (RPM). berdasarkan pada hasil analisis yang diuraikan dengan kesimpulan bahwa pada tahun 2016 pinjaman bermasalah sebesar $7.40 \%$ (berada diantara 0 hingga 10\%), pada tahun 2017 rasio pinjaman bermasalah meningkat sebesar 7,70\% (berada dantara 0 hingga 10\%) dan pada tahun 2018 pinjaman bermasalah sebesar 8,35\% (berada diantara 0 hingga 10\%), ini berarti pada tahun 2016-2018 skor yang diperoleh adalah 4,0 dengan nilai 80 dan masuk dalam kategori Sehat, akan tetapi belum efektif karena pinjaman bermasalah dari tahun 20162018 terus mengalami kenaikan.
\end{abstract}

Kata Kunci :Analisis, Pengendalian, Piutang

Abstract
Analysis Of Accounts Receivable Control At The Indonesian Republic Employee Cooporative (KPRI) ToliToli Regerency Dharma WorksThe formulation of the problem $i$ is how the effectiveness of control of receivables in terms of the magnitude of problem loans during the last 3 years in the karya dharma tolitoli regency with the aim of knowing the effectiveness of control of receivables in the terms of the magnitude of problem loans during the last 3 years. KPRI karya dharma tolitoli regerency is located on stret Ra. Kartini number 17. This research uses descriptive quantitative data types, supported to obtain primary and secondary data that are more valid, and objective, subjects, and data were collected by observation, interview, documentation, and literature study. The analytical tool used is the ratio of protected loans to loans (RPM). Based on the results of the analysis outlined by the conclusion that in 2016 problems loans amounted to 7,40\% (between 0 to 10\%), in 2017 the ratio of problem loans increased by $6,70 \%$ (between 0 to 10\%) and at in 2018 problem loans amounted to 8,35\% (between 0 to 10\%), this means that in 2016-2018 the score obtained was 4,0 with a value of 80 and included in the healthy category, bot not yet effective because of bad loans from the year 2016-2108 continues to increase.

Keywords: Analysis, Control, Accounts Receivable 


\section{PENDAHULUAN}

Koperasi merupakan salah satu bentuk organisasi berbadan hukum yang bergerak dibidang perekonomian, dalam hal ini, koperasi melandaskan kegiatanya berdasarkan prinsip gerakan ekonomi rakyat yang berdasarkan atas asas kekeluargaan sesuai yang terkandung dalam UUD 1945 Pasal 33 ayat 1 "Perekonomian Disusun Sebagai Usaha Bersama Berdasarkan Asas Kekeluargaan". Prinsip-prinsip koperasi merupakan landasan pokok utama koperasi dalam menjalankan usahanya sebagai badan usaha dan gerakan ekonomi rakyat, prinsipprinsip tersebut adalah: kemandirian, keaangotaan bersifat terbuka, pengelolaan dilakukan secara demokratis, pembagian sisa usaha dilakukan secara adil sebanding dengan besarnya jasa yang teratas terhadap modal.

Ciri utama yang membedakan koperasi dengan badan usaha lainnya adalah keanggotaannya yang bersifat sukarela, adanya prinsip demokrasi dalam pengambilan keputusan, serta keikutsertaan para anggota secara aktif memperbaiki kehidupannya dan kehidupan masyarakat disekitarnya melalui karya dan jasa yang disumbangkan.

Koperasi dapat berdiri sendiri tanpa adanya ketergantungan terhadap pihak lain. dalam hal ini koperasi mengumpulkan dana dari para anggotanya berupa hasil donasi dari simpanan anggota seperti, simpanan wajib, simpanan pokok, maupun sumber lainnya sebagai modal dalam menjalankan usaha sesuai aspirasi dakebutuhan bersama dibidang ekonomi. Dalam usahanya koperasi akan lebih banyak menekankan pada pelayanan terhadap kepentingan anggota di bandingkan dengan pihak luar. Karena dalam koperasi, anggota bertindak sebagai pemilik sekaligus sebagai pengguna jasa dan usaha koperasi yang bersangkutan. Dengan kata lain koperasi merupakan badan usaha yang didirikan, dikelola, dimiliki, diawasi dan dimanfaatkan oleh anggotanya.

Koperasi mempunyai berbagai unit jenis usaha, salah satunya adalah usaha simpan pinjam, Koperasi Pegawai Republik Indonesia (KPRI) Karya Dharma merupakan salah satu koperasi yang memiliki usaha simpan pinjam tersebut. pada unit simpan pinjam tersebut koperasi memperoleh keuntungan paling besar. unit simpan pinjam pada koperasi ini memberikan pinjaman kredit terbatas pada anggota koperasi saja, dan dari pinjaman tersebut maka akan timbul piutang.

Piutang merupakan unsur penting dalam neraca, prosedur yang wajar dan carapengamanan yang cukup terhadap piutang penting bukan saja untuk keberhasilan perusahaan, tetapi juga untuk memelihara hubungan yang memuaskan dengan pelanggan. Piutang biasanya timbul karena adanya transaksi secara kredit antara pihak pembeli dan pihak penjual, biasanya sesuai dengan ketentuan atau kesepakatan bersama untuk aturan dan tata cara. akan tetapi dalam menjalankan usahanya sering kali koperasi mengalami berbagai masalah, hal itu merupakan hambatan yang dapat mengganggu kelancaran hidup koperasi, dimana setiap masalah yang timbul harus segera diatasi dengan mencarikan jalan keluar atau pemecahannya.

Pengendalian piutang merupakan salah satu usaha yamg dilakukan oleh koperasi dalam menangani kemungkinan resiko yang dapat terjadi, dimana koperasi membatasi besarnya pinjaman yang akan diberikan kepada anggotanya untuk mencegah besarnya resiko yang mungkin timbul sebagai akibat penjualan kredit itu sendiri. namun adanya unsur resiko dan ketidakpastian, trutama pada jasa pengkreditan mengharuskan adanya pengamanan terhadap kredit yang diberikan kepada anggotanya, agar tidak terjadinya 
kredit bermasalah yang merugikan. Kredit bermasalah dan kredit macetdapat dihindari dengan melakukan pengendalian dalam pemberian pinjaman. Pengendalian yang paling sederhana yaitu dengan melakukan penilaian "5 C" yaitu: karakter, kemampuan, kapital, koleteral, \& kondisi untuk menilai kemampuan nasabah itu sendiri ketika ingin mengajukan kredit, serta menilai kemampun dalam pengembalian Untuk melaksanakan pengendalian kredit atas dana yang tertanam pada piutang, maka manajer harus memperhatikan beberapa faktor yang perlu dipertimbangkan oleh manajer perusahaan. Menurut Rahayu dan suhayati (2013: 221) dikutip dalam Befilia (2017:3) Pengendalian intern merupakan suatu proses yang dipengaruhi oleh dewan komisaris, manajemen, personel lainnya dalam suatu entitas, yang dirancang untuk memberikan keyakinan memadai guna mencapai tujuan. Sedangkan pengendalian piutang menurut Hery (2014:206) dalam Natalia (2015:4) yakni proses pengamanan yang efesien dan efektif dilakukan atas piutang usaha, baik dari segi pengamanan atas perolehan fisik kas, pemisahan tugas, sampai pada tersedianyan catatan akuntansi yang akurat. Menurut lukman syamsuddin (2007:257), syarat kredit yang perlu diperhatikan oleh pihak manajer antara lain: 1. Biaya Administrasi, 2. Investasi dalam piutang. kredit serta kebijakan dalam pemberian kredit agar mampu menguragi resiko kredit yang mungkin terjadi.

Berdasarkan penjelasan di atas maka penulis tertarik untuk melakukan penilitian sehingga dapat mengetahui gambaran atau posisi atau keadaan piutang yang sebenarnaya dengan judul "Analisis Pengendalian Piutang Pada KPRI Karya Dharma Kabupaten Tolitoli" Berdasarkan uraian latar belakang yang dikemukakan diatas maka pokok permasalahan pada penelitian ini adalah Bagaimana efektivitas pengendalian selama 3 tahun terakhir pada KPRI Karya Dharma Kabupaten Tolitoli.

Penelitian ini dilakukan dengan mengambil rujukan penelitian lain yakni . Wendy (2018) dengan judul Analisis Sistem Pengendalian intern terhadap pemberian dan pelunasan piutang pada Koperasi Pegawai Negeri (KPN) Bahtera Bitung. System pengendalian intern pada Koperasi belum berjalan dengan efektif, sehingga sebaiknya perlu dilakukan penambahan personil/pengurus untuk menghindari rangkap tugas, dan juga sebaiknya manajer perlu menerapkan analisis 5C dalam menganalisis pemberian kredit. Frendy (2018) judul Analisis Pengendalian Piutang terhadap Resiko Piutang tak tertagih pada PT. Federal International Finance (FIF) manado dengan kesimpulan penelitian menyatakan pengendalian piutang telah berjalan dengan baik. Tetapi pihak perusahaan masih perlu melakukan pengawasan baik secara langsung maupun tidak langsung. Berdasarkan dari uraian latar belakang diatas maka yang menjadi rumusan masalah dalam penelitian ini adalah Bagaimana tingkat efektivitas pengendalian piutang selama 3 tahun terakhir pada KPRI Karya Dharma Kabupaten Tolitol.

\section{METODE PENELITIAN}

Jenis penelitian yang digunakan dalam penelitian ini adalah jenis penelitian Deskriptif Kuantitatif. Jenis penelitian kuantitatif adalah metode penelitian yang menggunakan data-data berupa angka sebagai alat menganalisis dan melakukan kajian penelitian (Kasiram,2008:14) Lokasi penelitian ini dilaksanakan di Kabupaten Tolitoli, dengan obyek penelitian Koperasi Pegawai Republik Indonesia (KPRI) Kharya Dharma yang terletak di Jln RA Kartini No 17. Diduga manajemen Koperasi Pegawai Republik Indonesia (KPRI) Karya Dharma Kabupaten Tolitoli belum efektif dalam melakukan pengendalian piutangnya. 
Adapun jenis data yang dibutuhkan dalam penelitian ini adalah data Kualitatif, Data Kuantitatif. Sumber data yang digunakan dalam penelitian ini berasal dari data Primer data data sekunder. Untuk memperoleh data yang dibutuhkan dalam penelitian, maka tehnik pengumpulan data yang dilakukan dengan caraObservasi, Wawancara Dokumentasi Studi pustaka.

Berdasarkan peraturan Deputi Bidang Pengawasan Kementrian Koperasi dan Usaha Kecil Dan Menengah Republik Indonesia Nomor : 06/PER/DEP.6/IV/2009 tentang pedoman penilaian kesehatan koperasi simpan pinjam koperasi dalam kualitas aktiva produktif yaitu:

Rasio Pinjaman Bermasalah Terhadap Pinjaman Yang Diberikan

$$
\frac{\text { Pinjaman Bermasalah }}{\text { Pinjaman Yang Diberikan }} \text { X 100\% }
$$

Untuk memperoleh rasio antara rasio resiko pinjaman bermasalah terhadap pinjaman yang diberikan, ditetapkan sebagai berikut:

1. Menghitung perkiraan besarnya resiko pinjaman bermasalah (RPM) sebagai berikut:

(1) $50 \%$ dari pinjaman diberikan kurang lancar (PKL);

(2) $75 \%$ dari pinjaman diberikan yang diragukan (PDR); dan

(3) $100 \%$ dari pinjaman diberikan macet (PM)

2. Hasil penjumlahan tersebut dibagi dengan pinjaman yang diberikan

$\mathrm{RPM}=\frac{(50 \% \times \mathrm{PKL})+(75 \% \times \mathrm{PDR})+(100 \% \mathrm{xPM})}{\text { Pinjaman Yang Diberikan }}$

Perhitungan penilaian:

(1)Untuk rasio $45 \%$ atau lebih diberi nilai 0

(2)Untuk setiap penurunan rasio $1 \%$ dari $45 \%$ nilai ditambah 2 , dengan maksimum nilai 100; dan

(3)Nilai dikembalikan dengan bobot nilai $5 \%$ diperoleh skor penilaian

Tabel 1. Standar perhitungan RPM

\begin{tabular}{cccc}
\hline Rasio (\%) & Nilai & $\begin{array}{c}\text { Bobot } \\
(\%)\end{array}$ & Skor \\
\hline$\geq 45$ & 0 & 5 & 0 \\
$40<\mathrm{x}<45$ & 10 & 5 & 0,5 \\
$30<\mathrm{x} \leq 40$ & 20 & 5 & 1,0 \\
$20<\mathrm{x} \leq 30$ & 40 & 5 & 2,0 \\
$10<\mathrm{x} \leq 20$ & 60 & 5 & 3,0 \\
$0<\mathrm{x} \leq 10$ & 80 & 5 & 4,0 \\
0 & 100 & 5 & 5,0 \\
\hline
\end{tabular}

Tabel 2. Penetapan Predikat Tingkat Kesehatan KSP

\begin{tabular}{cc}
\hline Skor & Predikat \\
\hline $80<\mathrm{x}<100$ & Sehat \\
\hline $60<\mathrm{x}<80$ & Cukup Sehat \\
\hline $40<\mathrm{x}<60$ & Kurang Sehat \\
\hline $20<\mathrm{x}<40$ & Tidak Sehat \\
\hline$<20$ & Sangat Tidak Sehat \\
\hline
\end{tabular}

Sumber: permen KUKM No 14/per/M.KUKM/XII/2009

1. RPM (Rasio Pinjaman Bermasalah) maka semakin efektive sistem adalah suatu perbandingan yang mengukur rasio pinjaman bermasalah terhadap pinjaman yang diberikan. Semakin rendah nilai yang diperoleh pengendalian piutang. Dan sebaliknya semakin tinggi nilai yang di peroleh maka semakin tidak efektive sistem pengendalian piutang, akan tetapi 
semakin tinggi skor yang diperoleh maka semakin baik tingkat kesehatan koperasi. Penggolongan pinjaman bermasalah:

Pinjaman kurang lancar (PKL, Pinjaman yang diragukan (PDR), Pinjaman macet (PM)

\section{HASIL DAN PEMBAHASAN}

Melalui Rapat Anggota pada tahun 1972 diputuskan membentuk koperasi pegawai negeri dengan nama KPN "Karya Dharma" Kabupaten Tolitoli yang berkedudukan di kelurahan panasakan kecamatan baolan Tolitoli. Jenis usaha yang dilakukan yaitu menyediakan kebutuhan pokok dengan besarnya simpanan Rp 500 dan Rp 1.000 per anggota setiap bulannya Selanjutnya dijuhkanlah usul untuk mendapatkan badan hukum dengan melengkapi persyaratan yang diperlukan kepada kepala kantor Wilayah Departemen Koperasi Sulawesi Tengah melalui penelitian dan berbagai pertimbangan maka disetujui permohonan tersebut dengan dikeluarkannya badan hukum No.040/BH/XIX Tanggal 14 Juni 1972.

Sejak tahun 1972-1979 Koperasi ini praktis berjalan dan pada tanggal 9 September 1979 dengan menetapkan keputusan yaitu antara lain:

1. Membubarkan pengurus lama dan mengativkan Koperasi Pegawai Karya Dharma Tolitoli

2. Memilih pengurus baru masa bakti 4 tahun yaitu sejak tahun 1979 sampai dengan 1984 sesuai peraturan perundang-undangan yang berlaku

3. Bidang usaha yang dilakukan yaitu USP dan US Waserda

4. Besarnya simpanan anggota terdiri dari: Golongan IV : Rp 5.000,- setiap bulan, Golongan III : Rp 4.000,- setiap bulan, Golongan I/II : Rp 3.000,- setiap bulan

5. Keanggotaaan
Keangotaan pegawai negeri sipil dalam lingkungan depertemen dalam negeri pada wilayah Daerah tingkat II kabupaten Tolitoli

Akan tetapi sejak tahun 2018 Koperasi menetapkan besarnya simpanan anggota disamaratakan terdiri dari: Simpanan pokok : Rp 10.000, Simpanan Wajib : Rp 25.000

Struktur Organisasi Koperasi Pegawai Republik Indonesia Karya Dharma Kabupaten Tolitoli: Pembin, Pengurus koperasi terdiri dari Ketua, Sekertaris dan Bendahara, Pengaws, Bagian umum, Anggota koperas

Pada tahun 2018 anggota tercatat kurang lebih sebanyak 820 orang pegawai negeri yang aktif sampaidengan tahun 2019 .

Kegiatan Usaha Koperasi Kegiatan usaha pada koperasi KPRI Karya Dharma bertujuan untuk menyediakan kebutuhan anggota \& meningkatkan kesejahtraan anggota pada khususnya. Unit usaha koperasi adalahMemberikan pinjaman kredit dan menampung simpanan anggota koperasi setiap bulan dengan jumlah simpanan yang sama untuk setiap bulannya

Untuk mencapai tujuan KPRI Karya Dharma, maka pimpinan badan usaha melaksanakan beberapa kebijakan yang mengarah pada pencapaian tujuan badan usaha. Kebijakan piutang yang dilakukan badan usaha diharapkan mampu memberikan keuntungan bagi badan usaha, karena hal tersebut menyangkut asset KPRI Karya Dharma maka perlu dilakukan pengendalian.

1. Penilaian Tingkat Kesehatan Koperasi Simpan Pinjam

2. Perincian mengenai tata cara penilaian KSP menggunakan pedoman sebagai berikut 
Tabel 3. Penetapan Predikat Tingkat Kesehatan KSP

\begin{tabular}{cc}
\hline Skor & Predikat \\
\hline $80<\mathrm{x}<100$ & Sehat \\
\hline $60<\mathrm{x}<80$ & Cukup Sehat \\
\hline $40<\mathrm{x}<60$ & Kurang Sehat \\
\hline $20<\mathrm{x}<40$ & Tidak Sehat \\
\hline$<20$ & Sangat Tidak Sehat \\
\hline
\end{tabular}

Sumber : Permen KUKM No 14/per/M.KUKM/XII/2009

Keterangan:

1. Skor yang diperoleh berdasarkan hasil perhitungan penilaian terhadap aspek kualitas aktiva produktif, kopeasi dipergunakan untuk menetapkan predikat tingkat kesehatan KSP yang dibagi dalam 5 (lima) golongan yaitu:

Tabel 4. Standar perhitungan rasio resiko pinjaman bermasalah terhadap pinjaman yang diberikan
1) Sehat

2) Cukup sehat

3) Kurang sehat

4) Tidak sehat

5) Sangat tidak sehat

2. Standar Perhitungan Resiko Pinjaman Bermasalah (RPM)

\begin{tabular}{cccc}
\hline Rasio & Nilai & $\begin{array}{c}\text { Bobot } \\
(0 \%)\end{array}$ & Skor \\
\hline$<45$ & 0 & 5 & 0 \\
$40<\mathrm{x} \leq 45$ & 10 & 5 & 0,5 \\
$30<\mathrm{x} \leq 40$ & 20 & 5 & 1,0 \\
$20<\mathrm{x} \leq 30$ & 40 & 5 & 2,0 \\
$10<\mathrm{x} \leq 20$ & 60 & 5 & 3,0 \\
$0<\mathrm{x} \leq 10$ & 80 & 5 & 4,0 \\
$=0$ & 100 & 5 & 5,0
\end{tabular}

Sumber : permen KUKM No 14/Per/M.KUKM/XII/2009, Tentang penilaian kesehatan koperasi

Pada tabel 4.2 dapat dilihat standar perhitungan RPM, dimana rasio $<45 \%$ diberi nilai 0 dengan bobot $5 \%$ dan hasil skornya adalah 0 , kemudian $40 \%$ hingga $45 \%$ diberi nilai 10 dengan bobot $5 \%$ dan hasil skornya adalah 0,5 , dan $30 \%$ hingga $40 \%$ diberi nilai 20 dengan bobot $5 \%$ dan hasil skornya adalah 1,0 , kemudian $20 \%$ hingga $30 \%$ diberi nilai 40 dengan bobot $5 \%$ dan hasil skornya adalah 2,0 kemudian $10 \%$ dan $20 \%$ diberi nilai 60 dengan bobot $5 \%$ dan skornya adalah 3,0 , dan $0 \%$ hingga $10 \%$ diberi nilai 80 dengan bobot $5 \%$ dan hasil skornya adalah 4,0 kemudian $=0 \%$ diberi nilai 100 dengan bobot $5 \%$ dan hasil skornya adalah 5,0

1) Perhitungan dan perkembangan rasio resiko pinjaman bermasalah terhadap pinjaman yang diberikan

2) Daftar piutang pada Koperasi Pegawai Republik Indonesia 
Tabel 5. Daftar piutang pada Koperasi Pegawai Republik Indonesia Kabupaten Tolitoli Priode 2016-2018

\begin{tabular}{|c|c|c|c|}
\hline Periode & Pinjaman Kurang & Pinjaman Diragukan (Rp) & $\begin{array}{c}\text { Pinjaman } \\
\text { Macet (Rp) }\end{array}$ \\
\hline 2016 & 44.390 .169 & 30.650 .000 & 28.350 .000 \\
\hline 2017 & 47.690 .124 & 35.150 .000 & 33.330 .000 \\
\hline 2018 & 49.350 .000 & 40.150 .000 & 39.210 .000 \\
\hline
\end{tabular}

Sumber: Koperasi Pegawai Republik Indonesia Karya Dharma

Pada tabel 4.3 dapat dilihat daftar RPM=

piutang Koperasi Pegawai Republik Indonesia KPRI Karya Dharma Kabupaten Tolitoli, Pada Tahun 2016-2018. Pada tahun 2016 pinjaman kurang lancar sebesar Rp 44.390.169, pinjaman diiragukan $\mathrm{Rp}$ 30.650.000, pinjaman macet Rp 28.350.000. Pada tahun 2016-2017 pinjaman kurang lancar meningkat sebesar Rp 3.299.955 pinjaman diragukan naik Rp 4.500.000 dan begitu pula pinjaman macet sebesar Rp 4.980.000. pada tahun 2017- 2018 pinjaman bermasalah kembali mengalami peningkatan dimana pinjaman kurang lancar sebesar $\mathrm{Rp}$ 1.659.876, pinjaman diragukan mengalami peningkatan pula sebesar Rp 5.000.000 dan pinjaman macet naik sebesar Rp 5.880.000.

1) Mengukur piutang bermasalah tahun 2016

$\mathrm{RPM}=$

$\frac{(50 \% \times \mathrm{PKL})+(75 \% \times \mathrm{PDR})+(100 \% \times \mathrm{PM})}{\text { Pinjaman Yang diberikan }}$

$\underline{(50 \% \times 44,390,169)+(75 \% \times 30,650,000)+(100 \% \times 28,350,000)}$

RPM $=$

$\underline{22,195,085+22,987,500+28,350,000}$

$983,086,926$

$\mathrm{RPM}=\frac{73,532,585}{983,086,926}$

$\mathrm{RPM}=7,40 \%$

Dari peritungan diatas, hasil rasio pinjaman bermasalah yang diperoleh adalah sebesar $7,40 \%$. rasio ini masuk dalam kategori sehat (berada diantara 0 hingga $10 \%$ ) maka nilainya adalah 80 jadi skor untuk rasio ini adalah 4,0.

2) Mengukur piutang bermasalah tahun 2017 $\frac{(50 \% \times \text { PKL })+(75 \% \times \text { PDR })+(100 \% \times \mathrm{PM})}{\text { Pinjaman Yang Diberikan }}$

RPM

$$
\text { Pinjaman Yang Diberikan }
$$

$\frac{(50 \% \times 47,690,000)+(75 \% \times 35,150,000)+(100 \% \times 33,330,000)}{1084,368,003}$ $1084,368,043$

$\mathrm{RPM}=\frac{23,845,062+26,362,500+33.330,000}{1,084,368,043}$

$\mathrm{RPM}=\frac{83,537,562}{1,084,368,043}$

$\mathrm{RPM}=7,70 \%$

Dari perhitungan diatas,rasio pinjamanbermasalah mengalami peningkatan menjadi $7,70 \%$ atau naik sebesar $0,30 \%$. Hal ini disebabkan karena pinjaman yang diberikan juga mengalami peningkatan serta pihak koperasi yang mengalami kesulitan dalam hal penagihan. Rasio ini juga masih (berada diantara 0 hingga $10 \%$ ) maka nilainnya adalah 80 jadi skor untuk rasio ini adalah 4,0. Dan, masih masuk dalam kategori Sehat.

3) Mengukur piutang bermasalah tahun 2018

$\mathrm{RPM}=$

$\frac{(50 \% \times \mathrm{PKL})+(75 \% \times \mathrm{PDR})+(100 \% \times \mathrm{PM})}{\text { Pinjaman Yang Diberikan }}$

$\mathrm{RPM}=$

$\underline{(50 \% \times 49,350,000)+(75 \% \times 40,150,000)+(100 \% \times 39,210,000)}$

$\mathrm{RPM}=$

$24,675,000+30,112,500+39,210,000$

RPM $=\frac{93,997,500}{1,125,071,934}$

$\mathrm{RPM}=8,35 \%$

Dari perhitungan diatas,rasio pinjaman bermasalah kembali mengalami peningkatan menjadi $8,35 \%$ atau naik sebesar $0,65 \%$. Hal ini disebabkan karena pinjaman yang diberikan juga mengalami peningkatan serta 
kesulitan pihak koperasi dalam pemotangan gaji para anggota yang tidak mencukupi.Rasio ini masih (berada diantara
0 hingga 10\%) maka nilainnya adalah 80 , adapun skor untuk rasio ini adalah 4,0. Dan masih masuk dalam kategori Sehat.

Tabel 6 Hasil Perhitungan RPM Priode 2016-2018

\begin{tabular}{ccc}
\hline Tahun & RPM & Kategori \\
\hline 2016 & 7,40 & Sehat \\
\hline 2017 & 7,70 & Sehat \\
\hline 2018 & 8,35 & Sehat \\
\hline
\end{tabular}

Dari hasil diatas dapat dianalisis bahwa Pada tahun 2016 RPM Sebesar 7,40\% (berada diantara 0 sampai 10) dan masih masuk dalam kategori sehat. Tahun 2016-2017 RPM mengalami peningkatan sebesar $7,70 \%$ atau meningkat sebesar $0,30 \%$ dari tahun sebelumnya, ini disebabkan karena pinjaman yang diberikan mengalami peningkatandan masih masuk dalam kategori sehat.Kemudian pada tahun 2017-2018 RPM kembali mengalami peningkatansebesar $8,35 \%$ atau meningkat sebesar $0,65 \%$ dari tahun sebelumnya, disebabkan juga karena besarnya jumlah pinjaman yang diberikan mengalami peningkatan pula. Oleh karena itu penting bagi koperasi melakukan pengendalian dalamhal resiko pinjaman bermaslah dengan cara melakukan langkah langkah sebagai berikut:

Ketika pinjaman masuk dalam kategori kurang lancar maka pihak koperasi harus melakukan penangihan secara intensif baik melalui telfon, surat atau bahkan mendatangi secara langsung. Namun ketika

pinjaman kurang lancar tidak dapat ditagih sesuai jangka waktu yang telah piutang.

Tabel 7 Rekapitulasi rasio resiko pinjaman bermasalah (RPM) Priode 2016-2018

Tahun

Perubahan Naik/(Turun)

\begin{tabular}{cccccc} 
Uraian & $\mathbf{2 0 1 6}$ & $\begin{array}{c}\mathbf{2 1 0 7} \\
(\mathbf{R p})\end{array}$ & $\begin{array}{c}\mathbf{2 0 1 8} \\
\mathbf{( R p )}\end{array}$ & $\begin{array}{c}\mathbf{2 0 1 6 - 2 0 1 7} \\
(\boldsymbol{\%})\end{array}$ & $\begin{array}{c}\mathbf{2 0 1 7 - 2 0 1 8} \\
(\mathbf{\%})\end{array}$ \\
\hline $\begin{array}{c}\text { Pinjaman } \\
\text { yang } \\
\text { diberikan }\end{array}$ & 983.086 .926 & 1.084 .368 .043 & 1.125 .071 .934 & 10,30 & 3,75 \\
\hline $\begin{array}{c}\text { Pinjaman } \\
\text { bermasalah }\end{array}$ & 73.532 .585 & 83.537 .562 & 93.997 .500 & 13,60 & 12,52 \\
\hline
\end{tabular}


Dari perhitungan diatas dapat dianalisis bahwa tahun 2016 pinjaman yang diberikan sebesar $\mathrm{Rp}$ 983.086.926, kemudian ditahun 2017 meningkat menjadi Rp 1.084.368.043 atau naik sebesar $\mathrm{Rp}$ 101.281.117 atau 10,30\%. Kemudian pada tahun 2018 pinjaman yang diberikan juga mengalami kenaikan $\mathrm{Rp} 40.703 .891$ atau sebesar 3,75\%. Sedangkan pinjaman bermasalah pada tahun 2016 adalah sebesar Rp 73.532.585. kemudian 2017 mengalami kenaikan sebesar Rp 10.004.977 atau 13,60\%. Pada tahun 2018 pinjaman bermasalah mengalami peningkatan kembali sebesarRp 10.459.938 atau 12,52\%. Jadi dapat disimpulkan presentasi peningkatan pinjaman bermasalah dari tahun 2016-2018 lebih besar dari presentasi pinjaman yang diberikan pihak koperasi kepada para anggota.

\section{KESIMPULAN DAN SARAN KESIMPULAN}

Berdasarkan pada hasil analisis dan pembahasan maka dapat disimpulkan bahwa Manajemen Koperasi Pegawai Republik Indonesia (KPRI) karya Dharma Kabupaten Tolitoli, belum efektif dalam mengendalikan piutangnya hal ini terlihat Kondisi pinjaman bermasalah pada KPRI karya dharma kabupaten tolitoli, selama 3 tahun terakhir selalu mengalami peningkatan, namun masih masuk dalam kategori sehat. peningkatan yang dimaksud yaitu pada tahun 2016 RPM sebesar 7,40\% (berada diantara 0 sampai 10\%) dan masuk dalam kategori sehat. Pada tahun 2017 RPM mengalami peningkatan sebesar 7,70\% disebabkan karena presentase jumlah piutang bermasalah jauh lebih besar dibandingkan dengan presentase jumlah pinjaman yang diberikan akan tetapi masih masuk dalam kategori sehat dan berada diantara (0 sampai 10\%). Begitu pula pada tahu 2018 RPM kembali mengalami peningkatan sebesar $8,35 \%$ disebabkan pula karena presentase jumlah pinjaman bermasalah jauh lebih besar dibandingkan dengan jumlah presentase pinjaman yang diberikan namun masih masuk dalam kategori sehat karena masih berada di antara (0 sampai 10\%). namunapabila kenaikan RPM terus menerus terjadi maka akan berpengaruh pada tingkat kesehatan koperasi itu sendiri, Oleh karena itu penting bagi koperasi untuk mempertimbangkan berbagai aspek dalam pemberian kredit guna mencegah besarnya pinjaman yang bermasalah semakin tahun semakin meningkat, sehingga dapat disimpulkan bahwa pengendalian piutang pada koperasi KPRI Karya Dharma Kabupaten Tolitoli selama tiga tahun terakhir belum efektif dalam hal pinjaman bermasalah.

\section{SARAN}

Pihak manajemen koperasi hendaknya dapat meningkatkan kegiatan pada upaya pengembalian piutang dalam hal ini menambah petugas penagih piutang agar pinjaman dapat lebih maksimal dalam hal pengembalian.Pada saat memberikan pinjaman, pihak koperasi sebaiknya lebih teliti dan selektif terhadap "5 C" yaitu karakter, kapasitas, kapital, koleteral dan kondisi, terutama pada aspek karakter hal ini sangat penting diperhatikan karena berhubunggan dengan sifat pribadi manusia itu sendiri, karena terkadang tertundanya tunggakan pada kredit yang lama, muncul disebabkan oleh kesengajaan dari anggota padahal dari sisi keuangan mampu untuk mengembalikan, dan penilaian ini sangat penting untuk diperhatikan ketika akan memberikan pinjaman atau dalam penerimaan anggota.

\section{UCAPAN TERIMAKASIH}

Puji dan Syukur kami panjatkan kehadirat Allaw Swt. Atas nikmat dan karuniahnya sehingga penelitian dapat diselesaikan sesuai dengan waktu yang 
direncankan. Sebagai rasa terimakasih, penulismenyampaikanpenghargaan yang setinggi-tingginyasaya ucapkan kepada Bapak Masri Arfandi, SE. MM. Selaku Ketua yang telah memberikan izin kepada saya untuk melakukan penelitian dan merespon penelitian ini dalam bentuk pemberian bantuan pendanaan penelitian. Begitu juga kepada Bapak Kepala LPPM yang telah membantu saya guna kelancaran penyelesaian penelitian ini. Mulai tahap persiapan penelitian sampai pada tahapan seminar hasil penelitian. Terima kasih juga saya ucapkan kepada rekan - rekan sejawat dosen yang telah membantu pemikiran melalui ide - ide dalam penyelesaian penelitian ini, dan juga adik - adik mahasiswa yang turut serta guna membantu saya dalam proses pengambilan data penelitian.

\section{DAFTAR PUSTAKA}

Alfi Rohmaning Tyas, 2014.Anslisis Tingkat Kesehatan Koperasi Simpan Pinjam Mukti Bina Usaha Kelurahan Muktisari Kota Banjar Jawa Barat

Agus Harjito dan Marsono, 2004. Manajemen Keuangan,Cetakan Ekonosia, Yogyakarta

Befilia, Astika Putri, 2017. Analisis Pengendalian Intern pada Sistem dan Prosedur Pemberian dan Pelunasan kredit Ketahanan Pangan dan Energi (KKPE) Petani. Universitas Brawijaya. Vol. 50. No. 1 September 2017.

Gunawan Adisaputra, 2003. Anggaran Perusahaan Yoyakarta BPEE, Universitas Gajah Mada

Harmono, 2009. Manajemen Keuangan, PT Bumi Aksara, Jakarta

Irham Fahmi, 2011. Analisis Laporan Keuangan, Penerbit Alfabeta, Bandung
James, 2012. Prinsip-Prinsip Manajemen Keuangan , Edisis 13 Jakarta : Salemba empat

Ikatan Akuntan Indonesia, 2009. Standar

Akuntasi Keuangan , PSAK No. 1

: Penyajian Laporan Keuangan , Jakarata : Salemba Empat

Kristina Damayanti Putri, 2017. Analisis tingkat kesehatan koperasi simpan pinjam(Studi kasus pada Koperasi Simpan Pinjam Wisuda Guna Rahaja), Lombok

Lukman Syamsudin, 2007, Manajemen Keuangan Perusahaan,Jakarta : PT Raja Grafindo Prasada

Natalia, Nurafifah. 2015. Analisis Pengendalian Internal Atas piutang pada PT. Gis. Jurnal Spirit Pro Patria. Vol 1.

Ninik ,2010. Manajemen Koperasi Jakarta : Cetakan Rineka Cipta Jakarta

Kasmir, 2014.Bank Dan Lembaga Keuangan Lainnya edisis revisi cet.18-jakarta : rajawali pers, 2017 Jakarta

Riyanto, 2003. Dasar-dasar Pembelajaran Perusahaan Edisi ke empat Yayasan Penerbit Fe UGM, Yogyakarta

Sugiyono, 2016.Metode Penelitian Manajemen Penerbit Alfabeta, Bandung

Sofyan Harahap, 2007. Teori akuntansi edisi Revisi 2011 Jakarta, Rajawali Pers 